\title{
Modified Composite Nanomaterials as Novel Approach to Dental Hygiene Formulation
}

\author{
Marah Mazen Mahmoud 1(D), Muhammad Ashraf Sabri ${ }^{1(\mathbb{D})}$, Elias Djilali ${ }^{2}{ }^{(\mathbb{D})}$,

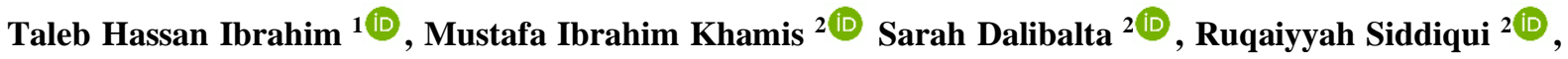 \\ Naveed Ahmed Khan 3 , ${ }^{\text {(D) }}$ \\ 1 College of Engineering, American University of Sharjah, Sharjah, 26666, United Arab Emirates; ${ }^{3}$ College of Medicine, \\ University of Sharjah, Sharjah, 27272, United Arab Emirates \\ 2 College of Arts and Sciences, American University of Sharjah, Sharjah, 26666, United Arab Emirates \\ 3 College of Medicine, University of Sharjah, Sharjah, 27272, United Arab Emirates \\ * Correspondence: naveed5438@gmail.com (N.A.K.);
}

Scopus Author ID 7401797675

Received: 7.09.2021; Revised: 16.10.2021; Accepted: 19.10.2021; Published: 26.10.2021

\begin{abstract}
Oral care and dental hygiene are integral parts of self-care. In the past few decades, there has been increased development in mouthwashes as oral care products. However, existing products may lead to a dry mouth or rely on ethanol. Herein, for the first time, we investigated the antibacterial effects of cetylpyridinium chloride, a cationic surfactant, intercalated with montmorillonite, a smectite clay to form a cetylpyridinium chloride-montmorillonite clay complex. Antibacterial assays revealed that the complex was able to eradicate oral bacteria in human saliva within 2 minutes, at a concentration of 0.05 $\mathrm{g} / \mathrm{L}$ as determined by plating human saliva onto nutrient agar plates post-treatment. These are very encouraging findings that could improve mouthwash formulations to remove stains and plaque against various oral bacteria.
\end{abstract}

Keywords: mouthwash; oral bacteria; cetylpyridinium chloride; antibacterials.

(C) 2021 by the authors. This article is an open-access article distributed under the terms and conditions of the Creative Commons Attribution (CC BY) license (https://creativecommons.org/licenses/by/4.0/).

\section{Introduction}

Oral health is an integral part of general health and cannot be over-emphasized for an individual's well-being. Inefficient self-care practices mainly related to dental hygiene can increase the incidence of oral diseases leading to serious health risks such as chronic diseases, heart attacks, and strokes [1]. According to the World Health Organization (WHO), the two most commonly widespread oral diseases are dental caries and periodontal diseases [2]. Dental caries alone is responsible for affecting 2.5 and 0.5 billion adults and children respectively worldwide $[3,4]$. According to the WHO, oral diseases are prominent in high- and low-income communities alike [5,6]. Despite advances, the Middle East has experienced a rise in the prevalence of oral diseases, possibly due to (i) low levels of awareness regarding dental hygiene and self-care practices, (ii) high levels of sugar consumption, and (iii) increased levels of smoking and tobacco usage [7,8]. Unhealthy lifestyle habits, coupled with inadequate preventive and restorative dental medicine, may have contributed to the development of common dental ailments in the region [9]. These ailments include, but are not limited to dental caries, periodontal diseases, oral precancerous lesions, and cancer [9]. A recent study was conducted on 5-year-old children in the United Arab Emirates to determine the level of dental 
caries in primary teeth. The data revealed that $83 \%$ of children had experienced dental caries and $52 \%$ suffered tooth decay [10].

Extensive research on toothpaste, flossing, and rinsing with mouth wash has been conducted for the prevention and/or eradication of oral diseases. Several antibiotics and antiseptics such as chlorhexidine and cetylpyridinium chloride (CPC) have been incorporated into oral rinses, gels, and toothpaste [11-14]. The use of such antibacterials and antibiotics is in the inactivation or inhibition of oral bacteria $[15,16]$. Though useful, the prolonged use of antibacterial agents is controversial due to their side effects (17-19]. Excessive use of antibacterials and antibiotics can increase the risk of inducing resistance in bacteria $[19,20]$. Moreover, many types of mouthwash or rinses rely on alcohol, which may increase xerostomia (dry mouth) or may contribute to oral cancer [21].

There are over 700 bacterial phylotypes present in the oral cavity, and while some of them are subject-specific, some are site-specific. Most bacterial families in the oral cavity are anaerobes or facultative anaerobes, allowing the bacterial strains to exist in the presence or absence of oxygen [22]. The overall aim of the present study was to test an alternative method, with fewer adverse effects, for bacterial removal that may be utilized with mouthwash or in toothpaste. This investigation formulated a novel complex formed by the intercalation of CPC with montmorillonite clay and then evaluated the antibacterial effects of this complex against selected oral bacteria present in human saliva.

\section{Materials and Methods}

Clay (Montmorillonite K10, surface area: 220-271 $\mathrm{m}^{2} / \mathrm{g}$, CAS: 1318-93-0) and cetylpyridinium chloride monohydrate (CAS: 6004-24-6) were purchased from SigmaAldrich. Cetylpyridinium chloride monohydrate (CPC) concentration in water was determined using an ultraviolet-visible (UV-VIS) spectrophotometer at a wavelength of $259 \mathrm{~nm}$. A temperature-controlled flask shaker was used for mixing and temperature control. Fourier Transfer-Infra Red (FT-IR) spectroscopy (Bomem MB-3000 equipped with ZnSe optics and a DTGS detector) was used to analyze the functional groups on the sample's surface. In addition, a scanning Electron Microscope (SEM) was used to analyze the surface morphology of the sample.

\subsection{CPC-clay complex preparation.}

The complex preparation was carried out by intercalation of CPC particles on montmorillonite clay to form the CPC-Clay complex (CCC). Stock CPC solution of $0.04 \mathrm{M}$ was prepared by dissolving CPC in $1 \mathrm{~L}$ of distilled water. The stock CPC solution was diluted with distilled water to the desired concentration before experimentation. The CPC calibration curve was prepared by CPC solution absorbance measurements with known CPC concentrations at $259 \mathrm{~nm}$ using a UV-Vis spectrophotometer. $1 \mathrm{~g}$ of clay was added gradually (over a time period of 10 minutes) to $100 \mathrm{~mL}$ of CPC solution of known concentrations and agitated at $150 \mathrm{rpm}$ for 24 days at $25^{\circ} \mathrm{C}$. The CPC concentration before and after CPC-Clay intercalation was quantified spectrophotometrically at $259 \mathrm{~nm}$. The amount of CPC intercalated on clay was calculated using this equation:

$$
q_{t}=\frac{C_{o}-C_{t}}{m_{a d / v}}
$$


where, $\mathrm{q}_{\mathrm{t}}$ and $\mathrm{m}_{\mathrm{ad} / \mathrm{v}}$ denote the mass of CPC intercalated as per the unit mass of clay $(\mathrm{mg} / \mathrm{g})$ at a given time and the mass of clay per unit volume used $(\mathrm{g} / \mathrm{L}) . \mathrm{C}_{\mathrm{o}}$ and $\mathrm{C}_{\mathrm{t}}$ refer to the CPC concentrations of the sample before and after intercalation $(\mathrm{mg} / \mathrm{L})$, respectively. Experiments were accomplished at different experimental parameters: contact time ( $0-24$ hours $)$, temperature $\left(25-60^{\circ} \mathrm{C}\right)$, shaking speed $(100-250 \mathrm{rpm})$, and initial CPC concentration $(0-0.04$ M) to determine the optimum intercalation parameters of CPC-Clay complex formation. The $\mathrm{CCC}$ formed was filtered using a vacuum filter. The solid residue was washed with ample water to ensure that no (or negligible $10{ }^{6} \mathrm{M}$ ) free-CPC leaches out of the $\mathrm{CCC}$ when stirred in water. The washed CCC was dried in a vacuum oven for 24 hours at $30^{\circ} \mathrm{C}$. The dried powder CCC was then stored in glass vials and kept in desiccators until further use.

\subsubsection{CPC-clay complex reversibility testing.}

To determine the reversibility of the CCC, $1 \mathrm{~g}$ of CCC was placed in $100 \mathrm{~mL}$ of distilled water and a shaker at $150 \mathrm{rpm}$ for five days. Samples from the mixture were taken at different time intervals, filtered, and the filtrate was analyzed for the $\mathrm{CP}+$ ions concentration in the solution spectroscopically to determine the reversibility of the complex, i.e., the release of $\mathrm{CP}+$ ions from the complex to the aqueous phase. The short term (few minutes) and long term (few hours to days) tests help in determining the reversibility of the CCC through standard teethbrushing duration (1-2 minutes) and shelf life (few days), respectively.

\subsubsection{Bactericidal assays.}

This study was approved by the Institutional Review Board of the American University of Sharjah (IRB Approval \# 45 CFR 46.110). One mL of saliva was obtained from three healthy subjects, and each sample was mixed with $99 \mathrm{~mL}$ of distilled sterilized water. To ensure equal distribution, the bottle was shaken 25 to 30 times thoroughly. This solution served as a control. Next, one $\mathrm{mL}$ from this diluted saliva sample was spread onto a nutrient agar plate, dried, and then the plates were incubated at $35^{\circ} \mathrm{C}$ to mimic oral temperature for 48 hours, after which bacterial colonies were enumerated. To determine the effectiveness of the novel CCC in eliminating oral bacteria, $1 \mathrm{~mL}$ of saliva was mixed thoroughly with $99 \mathrm{~mL}$ of different concentrations of CCC $(0.05 \mathrm{~g} / \mathrm{L}-1 \mathrm{~g} / \mathrm{L})$, and then samples were plated onto nutrient agar plates as described above. To determine the leachate effect, $0.05 \mathrm{~g} / \mathrm{L}-1 \mathrm{~g} / \mathrm{L}$ of CCC was stirred for 15 minutes in distilled water and filtered. The $\mathrm{CP}^{+}$ions leached out from the $\mathrm{CCC}$ (filtrate) were determined spectroscopically, and this solution was termed leachate. In a similar fashion, $1 \mathrm{~mL}$ of saliva was added to $99 \mathrm{~mL}$ of leachate and plated. Similar experiments were carried out with different concentrations of free CPC to determine the minimum CPC concentration needed to eliminate the oral bacteria within two minutes of interaction.

\section{Results and Discussion}

\subsection{Formation of CPC-clay complex.}

The analysis of the contact time effect on the intercalation efficiency of CPC is vital for determining the equilibrium time and the economic feasibility of the intercalation process. Figure 1a depicts the changes in the percentage CPC adsorption on clay as time varies from 0 to 24 hours. Stirring the CPC solution with the clay for a longer time was shown to have a significant effect. Initially, the CPC solution contained $1.28 \times 10^{-3}$ moles and, after stirring the 
mixture for four hours, approximately $50 \%$ of the CPC moles were intercalated with the clay. Upon stirring the mixture for a further 10 hours, the increase in adsorbed moles is much less pronounced, only going up to $\sim 55 \%$. Therefore, the optimum time was 10 hours, after which no significant increase in the adsorption of CPC on clay was observed. This longer time requirement can be explained in terms of diffusion and movability of the adsorbate size and mass as the intraparticle diffusion of large molecules of $\mathrm{CP}^{+}$to the porous network of the adsorbents is slow. The effect of the initial CPC concentration on the adsorption efficiency of the CPC is depicted in Figure. 1b. The percentage adsorption efficiency of CPC on clay decreased appreciably as the initial CPC concentration was increased. This can be attributed to the fact that the clay has a specific finite number of active sites available for adsorption and cation exchange capacity.

To determine the effect of temperature, the intercalation efficiency of CPC on clay was accomplished at five different temperatures ranging from $25,36,40$, and 50 and $60^{\circ} \mathrm{C}$, with $36^{\circ} \mathrm{C}$ mimicking the temperature in the oral cavity. The variations in the percentage of CPC adsorbed on clay with a temperature change were pronounced (Figure 1c). Increasing temperature from $25^{\circ} \mathrm{C}-60^{\circ} \mathrm{C}$ decreased adsorption from $60 \%$ to $49 \%$. This shows that the intercalation or the adsorption of CPC is likely an exothermal process. Hence, lower temperatures encourage intercalation of montmorillonite with CPC, whereas higher temperatures discourage intercalation with CPC from aqueous solutions.
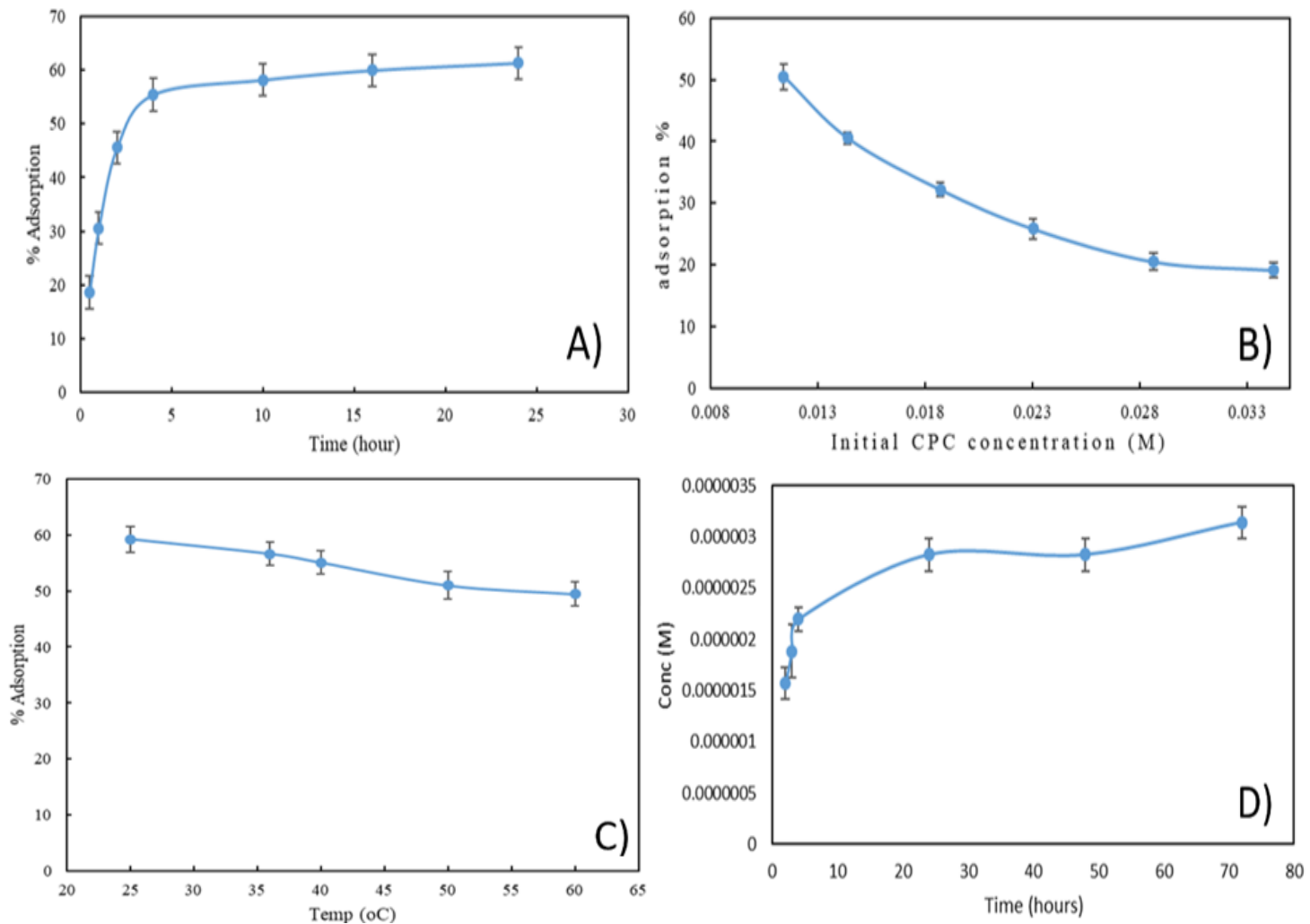

Figure 1. A) Effect of contact time on adsorption efficiency of CPC using clay. Experimental conditions comprise: clay dosage: $1 \mathrm{~g} / \mathrm{L}$, initial CPC concentration: $0.0144 \mathrm{M}$, temperature: $25^{\circ} \mathrm{C}$, solution volume: 100 $\mathrm{mL}$, and stirring speed: $150 \mathrm{rpm}$. B) Effect of initial CPC concentration on adsorption efficiency of CPC using clay. Experimental conditions comprise: clay dosage: $1 \mathrm{~g} / \mathrm{L}$, contact time: 24 hours, temperature: $25^{\circ} \mathrm{C}$, solution volume: $100 \mathrm{~mL}$, and stirring speed: $150 \mathrm{rpm}$. C) Effect of temperature on adsorption efficiency of CPC using clay. D) The irreversibility test of the complex.

Studying the reversibility of the complex is essential in determining the complex's stability and understanding the mechanism of complex-bacterial interaction. The reversibility 
test was carried out for samples synthesized at various contact times, different concentrations, and multiple temperatures. The results dictate that only $\sim 1-2 \%$ of the intercalated $\mathrm{CP}$ ions dissociated from clay. The concentrations of CPC in the leachate after one hour and three days were below the detection limits and within the order of magnitude of $10^{-6} \mathrm{M}$, respectively. The high stability of the complex could be attributed to different methods through which CPC may be intercalated with clay. CPC is initially adsorbed by the clay through ion exchange, a relatively irreversible process, but continues to form layers through hydrophobic interactions, which are reversible. Thus, the mixing of the complex with water should result in comparatively dilute leachate with a concentration in the order of $10^{-6} \mathrm{M}$ because most of the CPC moles are attached irreversibly.

\subsubsection{CPC-clay complex characterization.}

The surface structures for clay, CPC, and Clay-CPC complex were identified by SEM. Figure 2 displays the SEM images for clay, CPC, and Clay-CPC complex. It is evident that upon complexation, the size of the particles increases with a more homogeneous surface. This indicates that the complexation of CPC with clay resulted in a surface modification that might alter its surface activity.

a

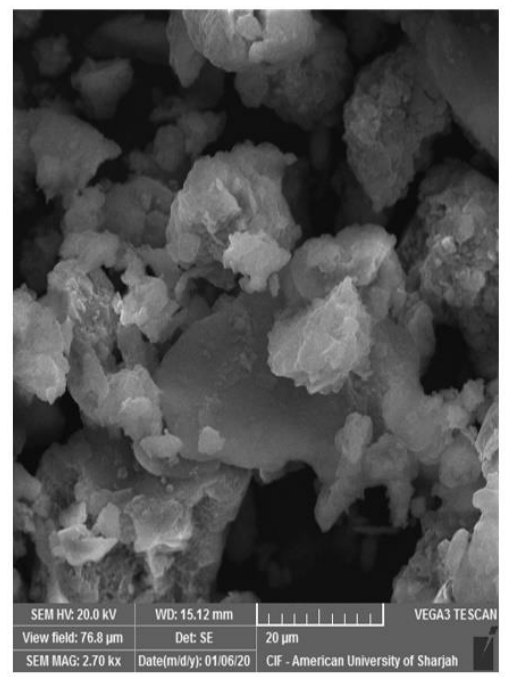

b-

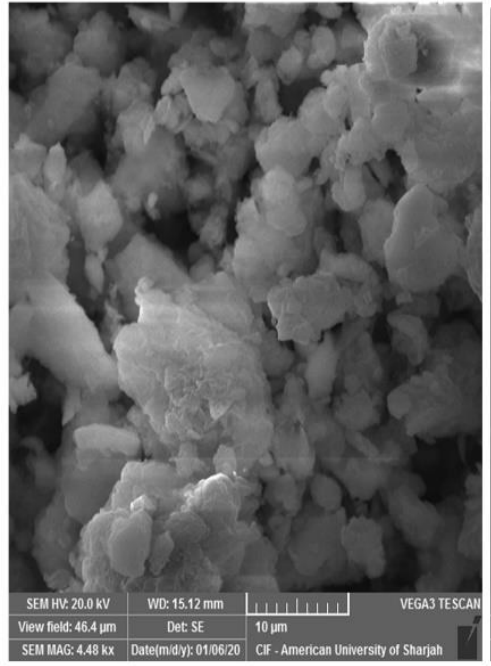

C

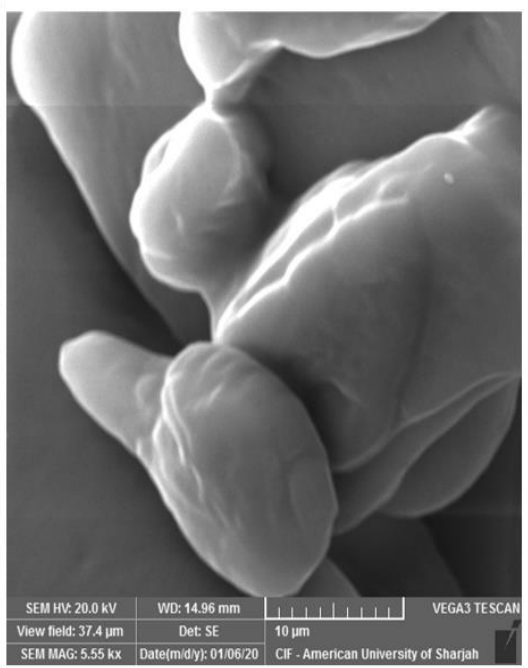

Figure 2. Representative scanning electron microscopic (SEM) images for (a) Clay; (b) CPC, (c) Clay-CPC complex.

The structures of the Clay, CPC, and Clay-CPC complex were characterized by FTIR spectroscopy (Figure 3). It is clear that the spectra of the complex indicate the successful complexation of clay with CPC. This is evident from the appearance of the peaks at 2921, 2850, and $1486 \mathrm{~cm}^{-1}$ in the complex spectra. Furthermore, the complexation led to the modification of the band at 3612. All these observations indicate the formation of the Clay-CPC complex.

\subsubsection{CPC-clay complex exhibited potent bactericidal activity.}

In order to determine the antibacterial properties of the complex, varying concentrations of CPC-clay complex were tested. Figure $4 \mathrm{a}$ and Table 1 show the effects of varying concentrations of the same CPC-clay complex on bacterial c.f.u. at various time intervals in comparison to without the CPC-clay complex, which depicted approximately 250 c.f.u. CPCclay complex revealed antibacterial activity at a minimum concentration of $0.05 \mathrm{~g} / \mathrm{L}$ and was 
able to eliminate bacteria after 2 minutes. Concentrations greater than $0.05 \mathrm{~g} / \mathrm{L}$ eliminated bacteria from the solution in less than 2 minutes. Overall, these results indicate that the complex does possess antibacterial properties, with $0.05 \mathrm{~g} / \mathrm{L}$ the minimum complex concentration required.
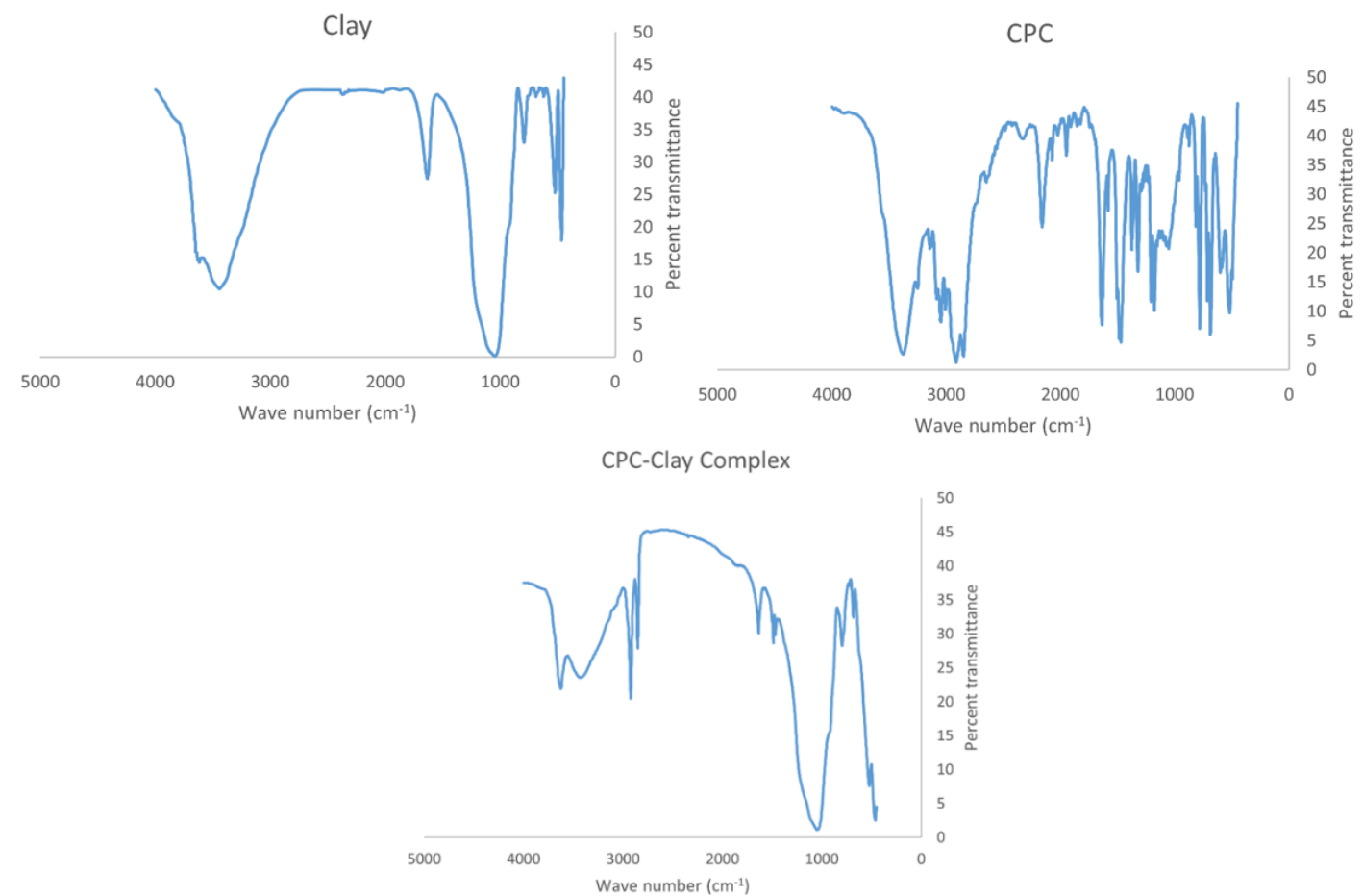

Figure 3. Representative Fourier Transform Infrared Spectroscopic (FTIR) spectra for clay, CPC, and CPC-clay complex.
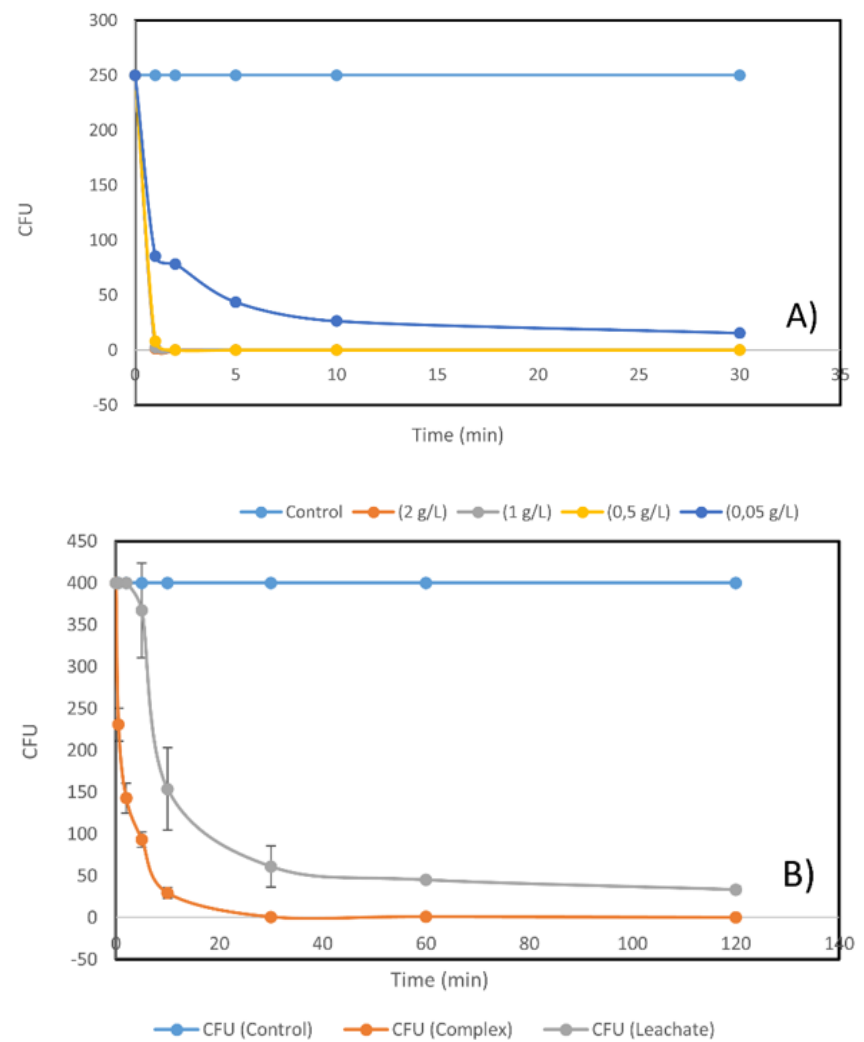

Figure 4. A) Effects of varying concentration of CPC-micelle complex on bacterial count. B) Effects of an unwashed complex prepared by shaking, and its leachate, on bacterial colonies over time. Note that CPCmicelle complex revealed antibacterial activity at a minimum concentration of $0.05 \mathrm{~g} / \mathrm{L}$ and is able to eliminate bacteria after 2 minutes. 
Furthermore, the effectiveness of the complex to that of the free CPC that leached out after being in contact with water was tested to ensure that the complexation with the clay enhanced the antibacterial properties. Figure $4 \mathrm{~b}$ shows the effects of the unwashed CPC-clay complex on CFU over time and compares them to the effects of its leachate. The results revealed that the bactericidal effects of the complex were greater than those of the leachate as the number of colonies decreased. The data demonstrate that the adsorption property of the clay may play a role in the mechanism of action of this complex. Within $1 \mathrm{~min}$, the number of c.f.u. were reduced to $85,8,4$, and 3 at $0.05 \mathrm{~g} / \mathrm{L}, 0.5 \mathrm{~g} / \mathrm{L}, 1 \mathrm{~g} / \mathrm{L}$ and $2 \mathrm{~g} / \mathrm{L}$ respectively. While at 2 min post-incubation, the number of c.f.u. was reduced to 78 , and 0 at $0.05 \mathrm{~g} / \mathrm{L}$, and $0.5 \mathrm{~g} / \mathrm{L}$, respectively.

Table 1. Effects of varying concentrations of CPC-micelle complex on bacterial colony-forming units count at various time intervals.

\begin{tabular}{l|l|l|l|l|l} 
Time (min) & Control & $\mathbf{2 g} / \mathbf{L}$ & $\mathbf{1 g} / \mathbf{L}$ & $\mathbf{0 . 5} \mathbf{g} / \mathbf{L}$ & $\mathbf{0 . 0 5} \mathbf{g} / \mathbf{L}$ \\
\hline 0 & 250 & 250 & 250 & 250 & 250 \\
\hline 1 & 250 & $3 \pm 1.53$ & $4 \pm 1.15$ & $8 \pm 10.6$ & $85 \pm 26.2$ \\
\hline 2 & 250 & 0 & 0 & 0 & $78 \pm 24.7$ \\
\hline 5 & 250 & 0 & 0 & 0 & $78 \pm 24.7$ \\
\hline 10 & 250 & 0 & 0 & 0 & $43 \pm 12$ \\
\hline 30 & 250 & 0 & 0 & 0 & $15 \pm 9.3$
\end{tabular}

Two complexes prepared using different initial CPC concentrations were tested to investigate whether a higher initial CPC concentration would provide a more potent bactericidal effect. Figure 5 shows that the greater the initial CPC concentration, the faster bacteria are eliminated from the saliva samples. The saliva samples used were diluted with a dilution factor of $10^{-2}$. The results also indicate that lysis plays a role in the way the complex operates, as it appears that greater CPC levels, which act by lysis, provide a greater bactericidal action. Next, the effects of the leachate were compared to those of a similar concentration of pure CPC to ensure that pure CPC and the leachate behaved similarly. The leachate obtained had a concentration of $1.16 \times 10^{-6} \mathrm{M}$, while the free CPC solution had a CPC concentration of $1 \times 10^{-6} \mathrm{M}$. Figure $5 \mathrm{~b}$ shows an overall similarity between the effects of free CPC and the leachate obtained from the complexes $(\mathrm{p}=0.37)$.

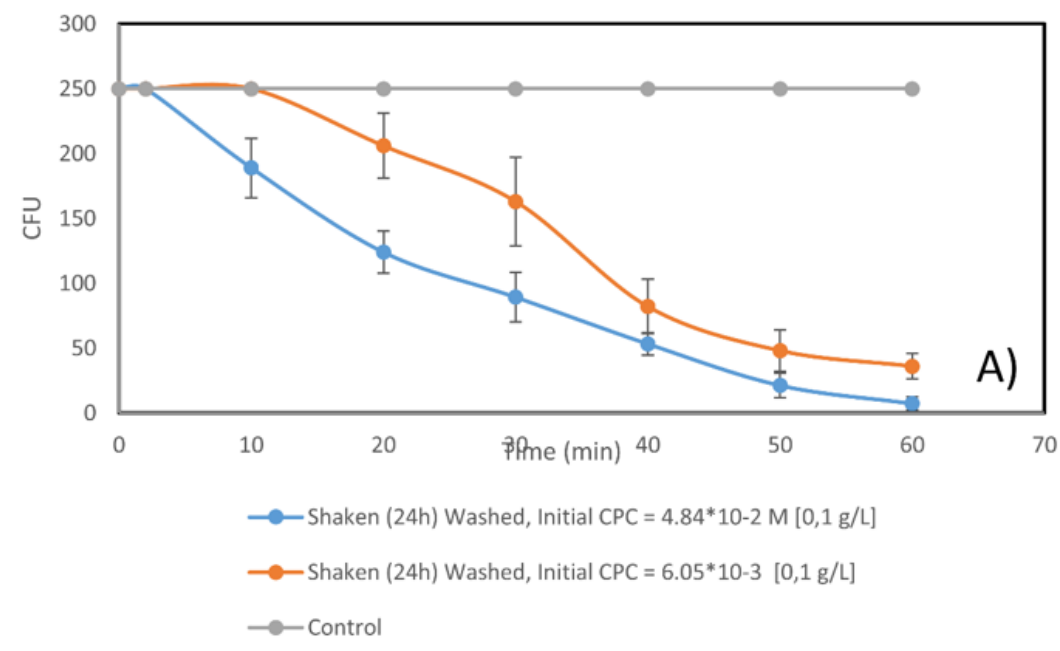




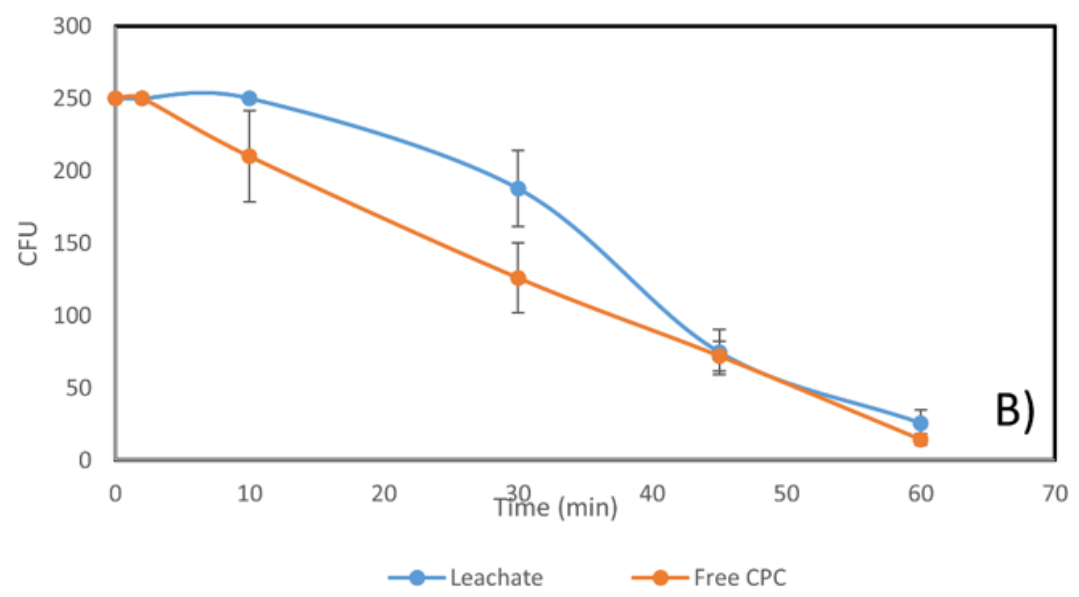

Figure 5. A) Effects of CPC-micelle clay complexes prepared using different initial CPC concentrations on CFU over time. B) Comparison of the effects of the leachate and free CPC over time.

The expanding market for oral care products has led to continued development in the formulation of innovative materials to improve further and augment oral health care routines [21]. Currently, alcohol is a major component of the majority of mouthwashes available. However, the utilization of high concentrations of ethanol may cause dryness as well as irritation to the mouth. Moreover, the use of alcohol in mouthwashes may increase the risk of oral cancers [23]. To overcome these issues and still deliver a similar quality of cleanliness, alcohol-free mouthwashes have been developed utilizing a blend of essential oils, ionic and non-ionic surfactants [21]. However, given the emergence of multidrug-resistant bacteria, there is a continuous need to improve oral care products. In the present study, we adopted a novel approach to developing a mouthwash with antibacterial properties. For the first time, cetylpyridinium chloride, a cationic surfactant, was intercalated successfully with montmorillonite, a smectite clay, to form a cetylpyridinium chloride-montmorillonite clay complex (CCC) to be utilized as a mouthwash or toothpaste which is capable of eliminating oral bacteria. The results revealed that $0.05 \mathrm{~g} / \mathrm{L}$ of CCC was capable of eliminating oral bacteria within 2 minutes. The antibacterial effect of the complex was superior to that of its leachate or free-CPC $\left(10^{-6} \mathrm{M}\right)$.

A limitation of this study was to determine the identity of bacterial species present in the saliva and/or determine CCC efficacy using purified bacterial colonies. However, the purpose of the study was to test the effects of CCC in eradicating bacterial colonies from selected saliva samples in vivo. We used a simple assay to demonstrate that CCC can eradicate bacteria. As samples were plated onto nutrient agar plates, it is unclear whether anaerobic bacteria and possibly other unculturable bacteria are affected by $\mathrm{CCC}$, which requires further investigation. In addition, there is a need to determine the effects of CCC on bacterial colonies from different populations as they likely represent varied microbial compositions.

\section{Conclusions}

To conclude, these results showed that CCC exhibit potent effects against culturable bacteria in human saliva. Reversibility tests confirm the stability of the complex and its promising use as an ingredient in toothpaste or other oral care products as an effective antibacterial agent in oral hygiene. While these are very promising findings, future studies are needed to investigate the effects of this novel CPC clay complex against the different types of 
oral bacteria (anaerobic and unculturable bacteria), molecular mode of action, as well as formulation of the complex for future commercial use.

\section{Funding}

This research received no external funding.

\section{Acknowledgments}

We are grateful to the American University of Sharjah, UAE, for supporting this work.

\section{Conflicts of Interest}

The authors declare no conflict of interest.

\section{References}

1. Petersen, P. E. The World Oral Health Report 2003: continuous improvement of oral health in the 21st century--the approach of the WHO Global Oral Health Programme. Community Dent Oral Epidemiol. 2003, 31, 3-23, https://doi.org/10.1046/j..2003.com122.x.

2. Beyth, N.; Houri-Haddad, Y.; Domb, A; Khan, W.; Hazan, R. Alternative antimicrobial approach: nanoantimicrobial materials. $J$ Evid Based Complementary Altern Med 2015, https://doi.org//10.1155/2015/246012.

3. Kassebaum, N.J.; Smith, A.G.; Bernabé, E.; Fleming, T.D.; Reynolds, A.E.; Vos, T.; Murray, C.J.L.; Marcenes, W.; and GBD 2015 Oral Health Collaborators. Global, regional, and national prevalence, incidence, and disability-adjusted life years for oral conditions for 195 countries, 1990-2015: a systematic analysis for the global burden of diseases, injuries, and risk factors. J Dent Res 2017, 96, 380-387, https://doi.org/10.1177/0022034517693566.

4. Grisolia, B.M.; Dos Santos, A.P.P.; Dhyppolito, I.M; Buchanan, H.; Hill, K.; Oliveira, B.H. Prevalence of dental anxiety in children and adolescents globally: A systematic review with meta-analyses. Int J Paediatr Dent 2021, 31, 168-183, https://doi.org/10.1111/ipd.12712.

5. Nazir, M.; Al-Ansari, A.; Al-Khalifa, K.; Alhareky, M.; Gaffar, B.; Almas, K. Global prevalence of periodontal disease and lack of its surveillance. Sci World J 2020, 2020, https://doi.org/10.1155/2020/2146160.

7. Petersen, P.E.; 2008. World Health Organization global policy for improvement of oral health-World Health Assembly 2007. Int Dent J 2007, 58, 115-121, https://doi.org/10.1111/j.1875-595x.2008.tb00185.x.

8. Elamin, A.; Garemo, M.; Mulder, A. Determinants of dental caries in children in the Middle East and North Africa region: a systematic review based on literature published from 2000 to 2019. BMC Oral Health 2021, 21, 1-30, https://doi.org/ 10.1186/s12903-021-01482-7.

9. Morgano, S.M.; Doumit, M.; Shammari, K.A.; Al-Suwayed, A.; Al-Suwaidi, A.; Debaybo, D.; Al-Mubarak, S. Burden of oral disease in the Middle East: opportunities for dental public health. Int Dent J 2010, 60, 197199, https://doi.org/10.1922/IDJ_2556Morgano03.

10. El-Nadeef, M. A.; Hassab, H.; Al-Hosani, E. National survey of the oral health of 5-year-old children in the United Arab Emirates. East Mediterr Health J 2010, 16, 51-5.

11. Rajendiran, M.; Trivedi, H.M.; Chen, D.; Gajendrareddy, P.; Chen, L. Recent Development of Active Ingredients in Mouthwashes and Toothpastes for Periodontal Diseases. Molecules 2021, 26, https://doi.org/10.3390/molecules26072001.

12. Levine, J.B.; Goncalves, J.; Nguyen, D.; Nguyen, O.; Hasturk, H. Efficacy of a novel post-foaming dental gel on gingival inflammation: A randomized controlled clinical trial. J Periodontol. 2020, 91, 1569-1583, https://doi.org/10.1002/JPER.19-0594.

13. Hoang, T.P.N.; Ghori, M.U.U.; Conway, B.R. Topical Antiseptic Formulations for Skin and Soft Tissue Infections. Pharmaceutics 2021, 13, https://doi.org/10.3390/pharmaceutics13040558.

14. Feitosa, S.; Carreiro, A.F.; Martins, V.M.; Platt, J.A.; Duarte, S. Effect of a chlorhexidine-encapsulated nanotube modified pit-and-fissure sealant on oral biofilm. Dent Mater J 2021, 40, 758-765, https://doi.org/10.4012/dmj.2020-241.

15. Quintas, V.; Prada-López, I.; Prados-Frutos, J.C.; Tomás, I. In situ antimicrobial activity on oral biofilm: essential oils vs. $0.2 \%$ chlorhexidine. Clinical oral investigations 2015, 19, 97-107, https://doi.org/10.1007/s00784-014-1224-3.

16. Barnett, M. L. The rationale for the daily use of an antimicrobial mouthrinse. J Am Dent Assoc 2006, 137, 121, https://doi.org/10.14219/jada.archive.2006.0408. 
17. Akbar, N.; Aslam, Z.; Siddiqui, R.; Shah, M.R.; Khan, N.A. Zinc oxide nanoparticles conjugated with clinically-approved medicines as potential antibacterial molecules. AMB Express 2021, 11, 1-16, https://doi.org/10.1186/s13568-021-01261-1.

18. Akbar, N.; Siddiqui, R.; Sagathevan, K; Khan, N.A. Gut bacteria of animals living in polluted environments exhibit broad-spectrum antibacterial activities. Int $\quad$ Microbiol 2020, 23, 511-526, https://doi.org/10.1007/s10123-020-00123-3.

19. Walsh, T.; Oliveira-Neto, J. M.; Moore, D. Chlorhexidine treatment for the prevention of dental caries in children and adolescents. Cochrane Database of Systematic Reviews 2015, https://doi.org/10.1002/14651858.CD008457.pub2.

20. Kampf, G. Acquired resistance to chlorhexidine-is it time to establish an 'antiseptic stewardship'initiative? $J$ Hosp Infect 2016, 94, 213-227, https://doi.org/10.1016/j.jhin.2016.08.018.

21. Aspinall, S.R.; Parker, J.K; Khutoryanskiy, V.V. Oral care product formulations, properties and $\begin{array}{lllll}\text { challenges. Colloids } \quad \text { and } \quad \text { Surfaces } & \text { Biointerfaces }\end{array}$ https://doi.org/10.1016/j.colsurfb.2021.111567.

22. Sedghi, L.; DiMassa, V.; Harrington, A.; Lynch, S.V.; Kapila, Y.L. The oral microbiome: Role of key organisms and complex networks in oral health and disease. Periodontol 2000 2021, 87, 107-131, https://doi.org/10.1111/prd.12393.

23. Currie, S.; Farah, C. Alcohol-containing mouthwash and oral cancer risk: a review of current evidence. $O A$ alcohol 2014, 2, https://espace.library.uq.edu.au/view/UQ:347891. 